\title{
THE USE OF PREDICTED APPARENT METABOLIZABLE ENERGY VALUES TO UNDERSTAND THE OIL AND FAT VARIABILITY IN BROILERS
}

\author{
Agnes THNG ${ }^{\star 凶}$, Jun Xiang TING, Hui Ru TAY, Chin Yi SOH, Hwee Ching ONG, David TEY \\ Kemin Industries (Asia) Pte Limited, Animal Health and Nutrition, 12 Senoko Drive, Singapore 758200, Singapore
}

*Email: agnes.thng@kemin.com

\begin{abstract}
The objective of this study was to analyze the predicted apparent metabolizable energy (AME) of different oil samples across Asia Pacific region and investigate the AME values in broilers of different ages $(<21$ or $>21$ days old). A total of 635 oil and fat samples consisting of 93 fish oils, 36 coconut oils, 70 crude palm oils, 42 refined palm oils, 43 soybean oils, 147 rice bran oils, 163 tallows and 41 lards were collected and analyzed over a span of eight years (2011 to 2018). The free fatty acid (FFA) content of oil and fat samples were analyzed through acid-base titration and the degree of saturation (ratio of unsaturation to saturated fatty acids; U:S) were determined with Gas Chromatography with Flame lonization Detector (GC-FID). The FFA and U:S of the samples were then incorporated into the Wiseman equation to correlate the oil and fat qualities with the AME. Our survey revealed AME variations were prevalent in most of the oil types studied, with fish oils and tallows showing the largest energy gap within oil samples. The results showed that the predicted AME values for oil and fat samples differ across countries, even within batches from the same supplier. Taken together, our investigation suggests that there is a considerable variation in the AME values of oils and fats, which may affect the feed formulation precision.
\end{abstract}

Keywords: Dietary energy, Fatty acid composition, Lipids, Oil quality, Poultry

\section{INTRODUCTION}

Vegetable oils and animal fats are usually added to animal diets to increase dietary energy concentration (Ravindran et al., 2016). Since oils and fats confer at least twice as much energy as other food nutrients such as carbohydrates and proteins (Ahiwe et al., 2018; Blair, 2018), there is a greater demand in optimizing the use of these products to meet the energy requirements of poultries (Ravindran et al., 2016). Furthermore, high fat feeding in poultry has been proven to improve the digestibility and absorption of non-lipid constituents (Blair, 2018). However, the quality of oils and fats are highly variable, and their digestibility are dependent on their chemical structures (Codony et al., 2017). Poor processing and storage conditions can also cause structural changes in oils and fats, leading to high fluctuations in the nutritional values (FAO/WHO, 2001; Gibson and Newsham, 2018).

Fat digestion consists of the emulsification of dietary fat with bile salt, followed by the enzymatic hydrolysis of triglycerides. The 2-monoglycerides, formed from partial hydrolysis of triglycerides, improve the solubility and absorption of free fatty acids through the formation of micelles (Pond et al., 2004; Scanes et al., 2019). As such, low levels of 2monoglycerides will result in incomplete micellar solubilization of free fatty acids. It was previously reported that the total micellar fatty acids were lowest in the duodenum of free fatty acid (FFA) - fed chicks where monoglycerides were present at trace level (Hofmann and Borgstrom, 1962; Sklan, 1979). In addition, fat digestion is also highly dependent on the degree of fatty acid saturation where Tancharoenrat et al. (2014) reported a higher digestibility with unsaturated fatty acids such as oleic acid and linoleic acid in comparison to saturated fatty acids such as palmitic and stearic acids. Additionally, the natural emulsifying properties of unsaturated fatty acids could also aid in mixed micelle formation and absorption, resulting in better utilization of saturated fatty acids (Rodriguez-Sanchez et al., 2019). Given the importance of FFA and the degree of saturation of oil (ratio of unsaturated to saturated fatty acids; U:S) in oil digestion and absorption, the Wiseman equation incorporates both of these parameters into one general equation to predict the energy values of different sources of oils and fats (Wiseman and Blanch, 1994).

As these macromolecules are important energy sources for animals, it is imperative for us to understand the variation of oil quality based on apparent metabolizable energy (AME) across countries and oil types, and its impacts on broilers. Previous reports showed that the fat utilization in broilers was age dependent where fat utilization improved with age (Rodriguez-Sanchez et al., 2019). Animal nutritionists often struggle to formulate feed with adequate energy intake due to the variation of the nutritional values in oil and fat samples that can lead to reduction in the performances of the 
animals and substantial economic losses (Niu et al., 2009; Ahiwe et al., 2018). A better understanding of the AME of different oil and fat samples can be gained by incorporating the FFA and U:S data into the Wiseman equation to generate information on the quality of the oil and fat samples; this will allow nutritionists to make informed decisions on their use for feed formulation to achieve consistent animal performance. In this study, the AME for oil and fat samples were determined based on the Wiseman equation to highlight the importance of accurate information on dietary energy value of feed.

\section{MATERIALS AND METHODS}

\section{Instrumentation}

DL 50 GRAPHIX auto-titrator (Mettler-Toledo, Ohio, United States) and DG113-SC glass electrode (Mettler-Toledo) were used to determine free fatty acid content. 7890B GC-FID (Agilent Technologies, California, United States) with Supelco SPTM-2560 (L $\times$ I.D. $100 \mathrm{~m} \times 0.25 \mathrm{~mm}$, df $0.20 \mu \mathrm{m}$ thickness) (Sigma-Aldrich, Missouri, United States) was used for chromatographic separation of fatty acid methyl esters (FAME).

\section{Sample collection and preparation}

A total of 635 oil and fat samples with plant and animal origins were collected across the Asia Pacific region and analyzed over a span of eight years from year 2011 to 2018. These samples included tallow, rice bran oil, fish oil, palm oil (crude and refined palm oil), soybean oil, lard and coconut oil. All samples were stored in plastic containers upon receipt and kept in the chiller at $2^{\circ} \mathrm{C}$ to $6{ }^{\circ} \mathrm{C}$. Before analysis, the samples were either thawed at room temperature or melted in the oven at $60^{\circ} \mathrm{C}$. All samples were analyzed within one week from the collection date.

\section{Free Fatty Acid (FFA) content}

The FFA content of oil and fat samples were determined with an in-house method, modified from the Association of Official Analytical Chemists (AOAC) method (AOAC, 2012). Fifty (50) $\mathrm{mL}$ of $95 \%$ ethanol (Aik Moh Paints and Chemical Pte Ltd, Singapore) was added to $1.0 \mathrm{~g}$ of oil or fat sample in a titration cup. The sample was stirred for $60 \mathrm{~s}$ under stirring speed of $50 \%$ with an auto-titrator. After stirring, titration was done with $0.1 \mathrm{~N}$ sodium hydroxide (Merck KGaA, Darmstadt, Germany) as the titrant using a $\mathrm{pH}$ sensor with measurement mode set as equilibrium controlled. The result was calculated from the volume consumption of the sodium hydroxide titrant and its concentration. Based on the oil type, the FFA content is expressed either as \% oleic acid, \% palmitic acid or \% lauric acid.

\section{Fatty Acid Methyl Esters (FAME) composition analyses}

FAME composition of oil and fat samples were determined using an in-house method, with modification from Association of Official Analytical Chemists (AOAC) method (AOAC, 2012). Four $\mathrm{mL}$ of $2 \%$ (w/v) methanolic sodium hydroxide (Merck) was added to $40 \mathrm{mg}$ of fat or oil sample and refluxed until there were no visible fat globules. $5 \mathrm{~mL}$ of $14 \%$ boron trifluoride in methanol (Sigma-Aldrich) was added and refluxed for another 2 mins. Finally, $10 \mathrm{~mL}$ of heptane (Sigma-Aldrich) was added and refluxed for another $1 \mathrm{~min}$. Subsequently, the content was cooled to room temperature. Next, $15 \mathrm{~mL}$ of $26 \%(\mathrm{w} / \mathrm{v}$ ) sodium chloride (Merck) was added and swirled vigorously. The top organic layer (heptane) was filtered through sodium sulphate (Merck) and injected into the GC-FID for chromatographic separation. Extracted samples were analyzed with helium at a flow rate of $0.85 \mathrm{~mL} / \mathrm{min}$ as carrier gas and a split ratio of 40:1. Injection volume was set at $0.4 \mu \mathrm{L}$ with injection port temperature set at $260^{\circ} \mathrm{C}$. The $\mathrm{GC}$ oven temperature was programmed at $140{ }^{\circ} \mathrm{C}$ for the first 5 mins and raised to $235{ }^{\circ} \mathrm{C}$ at $5{ }^{\circ} \mathrm{C} / \mathrm{min}$ for $15 \mathrm{mins}$, followed by $15{ }^{\circ} \mathrm{C} / \mathrm{min}$ to $250{ }^{\circ} \mathrm{C}$ for 5 mins. The total run time was 45 mins. Percentage composition of each FAMEs in oil and fat samples were calculated with Supelco 37 component Fatty Acid Methyl Esters (FAME) Mix certified reference material (CRM) (Sigma-Aldrich) as reference standard.

\section{Data analysis}

\section{Prediction of Apparent Metabolizable Energy (AME) using Wiseman equation}

AME of samples were predicted using a general equation (Equation 1) with A, B, C and D based on the values shown in Table 1 (Wiseman and Blanch, 1994; Wiseman et al., 1998).

$A M E(M J / k g$ fat $)=A+B * F F A+C * e^{D(U / S)}$

\section{Apparent Metabolizable Energy (AME) variation}

AME range was calculated as the difference between the highest and lowest predicted AME values whereas relative variations were calculated as the ratio of calculated range against lowest predicted AME or literature AME.

\section{Statistical analyses}

Single measurement data were calculated for the AME of each oil type. Descriptive statistics were calculated using Microsoft Excel 365 and presented in Table 3. 
Table 1 - Empirical values of constants A - D used in Wiseman equation to predict the apparent metabolizable energy (AME) values of poultry at different ages

\begin{tabular}{lcc} 
Constant (unit) & Young broilers $(<21$ days) & Old broilers $\left(>21\right.$ days) $^{\mathrm{a}}$ \\
\hline A (MJ/kg) & $38.112 \pm 1.418$ & $39.025 \pm 0.557$ \\
B (MJ/kg) & $-0.009 \pm 0.002$ & $-0.006 \pm 0.001$ \\
C (MJ/kg) & $-15.337 \pm 2.636$ & $-8.505 \pm 0.746$ \\
D & $-0.506 \pm 1.186$ & $-0.403 \pm 0.088$ \\
\hline a Empirical values of constants A - D were categorized into two groups, young broilers (aged < 21 days) and old broilers (aged > 21 days). All \\
young broilers (aged < 21 days) followed the same empirical values for constants A - D, likewise for old broilers (aged > 21 days).
\end{tabular}

\section{RESULTS}

Predicted Apparent Metabolizable Energy (AME) values for all samples

Using GC-FID and acid-base titration, all samples were analyzed for their lipid composition and FFA content (Table 2). Descriptive analysis of eight different oil types were presented in Table 3. AME of young broilers (aged $<21$ days) and old broilers (aged $>21$ days) were studied in this paper. Based on the GC-FID analyses, it was determined that the U:S for crude palm oil was lowest amongst all samples analyzed while the U:S for soybean oil was the highest, with relatively low FFA content of $1.01 \%$ oleic acid recorded (Table 3 ). When the data was further extrapolated using Equation 1, it was found that the highest predicted mean AME values were from soybean oil, at $8362 \mathrm{kcal} / \mathrm{kg}$ (young broilers) and $8672 \mathrm{kcal} / \mathrm{kg}$ (old broilers). On the other hand, the lowest predicted mean AME values were from crude palm oil with the predicted AME values at $6617 \mathrm{kcal} / \mathrm{kg}$ (young broilers) and $7669 \mathrm{kcal} / \mathrm{kg}$ (old broilers) (Table 3).

It was apparent that the predicted AME values were inconsistent across all oil samples. In particular, a large spread of AME for fish oil samples for different age groups of broilers was observed. The energy gaps for young ( $<21$ days old) and old broilers (> 21 days old) were $2295 \mathrm{kcal} / \mathrm{kg}$ and $1417 \mathrm{kcal} / \mathrm{kg}$, with a relative variation of $36 \%$ and $19 \%$ respectively (Table 3). The AME gap for crude palm oil for young ( $<21$ days old) and old broilers ( $>21$ days old) were found to be $1057 \mathrm{kcal} / \mathrm{kg}$ and $540 \mathrm{kcal} / \mathrm{kg}$ with relative variations of $17 \%$ and $7 \%$ (Table 3). Comparatively, refined palm oil also showed a smaller AME spread relative to crude palm oil, with $506 \mathrm{kcal} / \mathrm{kg}$ for young broilers (8\% variation) and $250 \mathrm{kcal} / \mathrm{kg}$ for old broilers (3\% variation) (Table 3). As the three major oil groups (e.g. tallow, rice bran oil, and fish oil) accounted for $63 \%$ of the total oil and fat samples collected and represented the majority of the oil and fat products (Table 2), the data for these groups were further analyzed (Table 4).

\section{Tallow}

Large AME discrepancy of $2670 \mathrm{kcal} / \mathrm{kg}$ for young broilers with relative variation of $49 \%$ and $1565 \mathrm{kcal} / \mathrm{kg}$ for old broilers with a relative variation of $23 \%$ were observed (Table 3). Out of 163 samples, $85 \%$ of the samples were received from five different sources originating from South Korea (Table 4). Majority of the samples were from the same source, supplier 1, where it accounted for approximately $78 \%$ of the tallow samples received from South Korea. Large spread of AME was observed for supplier 1, at $1248 \mathrm{kcal} / \mathrm{kg}$ with a relative variation of $20 \%$ for young broilers and $626 \mathrm{kcal} / \mathrm{kg}$ with a relative variation of $8 \%$ for old broilers (Figure 1). As such, supplier 1 from South Korea was singled out with samples collected in eight batches over a span of five years, from year 2012 to 2016. The AME values observed were inconsistent even within batches where the energy spread was in the range of $230 \mathrm{kcal} / \mathrm{kg}$ to $1063 \mathrm{kcal} / \mathrm{kg}$ with relative variation of $3 \%$ to $17 \%$ (Table 5). Likewise, AME values for tallow samples from supplier 3 were inconsistent as well, with energy spread at $1362 \mathrm{kcal} / \mathrm{kg}$ for young broilers (aged < 21 days) and $740 \mathrm{kcal} / \mathrm{kg}$ for old broilers (aged > 21 days) (Figure 1). This translated to relative variations of $20 \%$ for young broilers (aged $<21$ days) and $10 \%$ for old broilers (aged $>21$ days).

\section{Rice bran oil}

All rice bran oil samples received were from Thailand since 2012. From 2012 to 2014, the predicted ME values were highly variable as shown in Figure 2. However, from 2015 onwards, the predicted AME values were calculated to be more consistent where the energy values ranged from $7500 \mathrm{kcal} / \mathrm{kg}$ to $8000 \mathrm{kcal} / \mathrm{kg}$ (relative variation of $7 \%$ ) with only seven outlier samples. High FFA content of $12.50 \%$ oleic acid was observed (Table 3 ).

\section{Fish oil}

Majority of the fish-based oil samples were from Indonesia and Thailand (63\% of fish oil samples). Figure 3 showed that fish oils from Thailand consisted of large energy gaps of $2295 \mathrm{kcal} / \mathrm{kg}$ (young broilers) and $1417 \mathrm{kcal} / \mathrm{kg}$ (old broilers). Similarly, when the AME for different batches of fish oils from the same supplier (supplier A) in Thailand were determined, it was found that the AME ranged from $6442 \mathrm{kcal} / \mathrm{kg}$ to $8738 \mathrm{kcal} / \mathrm{kg}$ with relative variation of $36 \%$ in young broilers (Table 4). Likewise, a difference of $1926 \mathrm{kcal} / \mathrm{kg}$ in terms of AME variation (30\%) was observed between fish oil samples from Indonesia (Table 4). 
The quality and efficiency of feed formulations are highly dependent on two main factors, the extent and accuracy of animal nutritionists' knowledge on raw materials' qualities and compositions, as well as the nutrient requirements of targeted species (Lall and Dumas, 2015). Animal nutritionists struggle to formulate feed with adequate energy when lipid energy values stated in traditional feed tables often deviate from the actual energy value due to various reasons such as poor storage and processing conditions. It is also likely that these values did not account for the species and age dependent metabolism. While Baião et al. (2005) reported that the AME for tallow was in the range of $7000 \mathrm{kcal} / \mathrm{kg}$, Figures $1(A)$ and $1(B)$ indicated that regardless of animal age groups, inconsistency in AME values of tallow were apparent where energy variations occurred even within the same supplier with relative variation as high as $17 \%$ for the same batch of tallow samples. Without proper lipid quality evaluations, this will eventually lead to poorer animals' performances and economic losses.

The predicted mean AME of soybean oil is the highest as compared to other oil types. One of the main contributing factors is the presence of high unsaturated fatty acids where the recorded U:S ratio was 4.71 (Table 3). Consistent to a previous study conducted by Rodriguez-Sanchez et al. (2019) where it was reported that hydrolysis in unsaturated diets were relatively more efficient than saturated diets which results in higher digestibility and absorption. The AME of soybean oil ranged from $6665 \mathrm{kcal} / \mathrm{kg}$ to $8796 \mathrm{kcal} / \mathrm{kg}$ for young broilers (aged < 21 days) and $7716 \mathrm{kcal} / \mathrm{kg}$ to $8997 \mathrm{kcal} / \mathrm{kg}$ for old broilers (aged > 21 days). In comparison, a study showed that the AME of soybean oil is at 8790 $\mathrm{kcal} / \mathrm{kg}$ (Baião et al., 2005), demonstrating $12 \%$ relative variation from the literature value. Low fatty acid content (1.01\% oleic acid) was also observed for soybean oil. The presence of high FFA decreases bile secretion which in turns reduces micellar formation, leading to poor absorption of digested materials (Ravindran et al., 2016; Rodriguez-Sanchez et al., 2019). A study conducted by Wiseman and Salvador (1991) showed that AME is inversely proportional to the FFA content, with the effect being more pronounced in younger broilers. In agreement with the study conducted by Wiseman and Salvador, our survey also showed that the AME values of young broilers were more divergent as compared to older broilers, demonstrating their sensitivity to oil quality variations possibly due to less developed physiological capacity in fat utilization (Rodriguez-Sanchez et al., 2019).

Our results showed that from year 2015 onwards, the AME values for rice bran oil samples collected from Thailand were more consistent (Figure 2). One plausible reason could be due to technological improvements made to the manufacturing or transporting processes in Thailand. While more consistent AME values were observed over the years, the FFA content of rice bran oil remains the highest among the eight oil types analyzed (Table 3). As rice bran contains endogenous lipase capable of digesting and hydrolyzing the triglycerides present to form FFA (Goffman and Bergman, 2003, Vallabha et al., 2015), it is possible that the samples collected were likely to be extracted from poor quality rice bran where the triglycerides had been hydrolyzed (Rajan and Krishna, 2009). Interestingly, while high FFA content was observed in rice bran oil (Table 3), its AME remains one of the highest among the other oil types. One of the reasons could be due to the relatively higher U:S where the presence of unsaturated fats aid in the solubilization and absorption of FFA (Hofmann and Borgstrom, 1962).

Large energy gaps were observed in fish oil with $36 \%$ variation in young broilers ( $<21$ days) and $19 \%$ variation in old broilers (> 21 days). This is likely due to the presence of different fish oils with different oil quality grades such as salmon fish oil and crude tuna fish oil. There are different standards for different fatty acid compositions of different fish origins. For instance, while the standard for $\mathrm{C22:6}(\mathrm{n}-3)$ docosahexaenoic acid of tuna oil ranges from 21.0 - $42.5 \%$ of total fatty acids, similar standard for wild salmon oil ranges from 6.0 - 14.0\% (FAO/WHO, 2017). Fish oils are also susceptible to lipid oxidation due to the high degree of unsaturation (European Food Safety Authority (EFSA, 2010) where unsaturated fatty acids are prone to oxidation (Dominguez et al., 2019). Comparatively, refined palm oil has lower AME spread as compared to crude palm oil. This is likely due to the refining processes that may have possibly removed the impurities, and therefore confers a more consistent oil quality in refined palm oil.

Given these analyses, it is evident that having a proper lipid analysis in place is fundamental for accurate estimation of dietary energy in feed formulations.

Table 2 - Number of oils and fats collected across Asia Pacific region, per oil type

\begin{tabular}{lc} 
Oils and fats & Count \\
\hline Tallow & 163 \\
Rice bran oil & 93 \\
Fish oil & 70 \\
Crude palm oil & 43 \\
Soybean oil & 42 \\
Refined palm oil & 41 \\
Lard & 36 \\
Coconut oil & \\
\hline
\end{tabular}


Table 3 - Descriptive analysis data of the eight different oil types for broilers

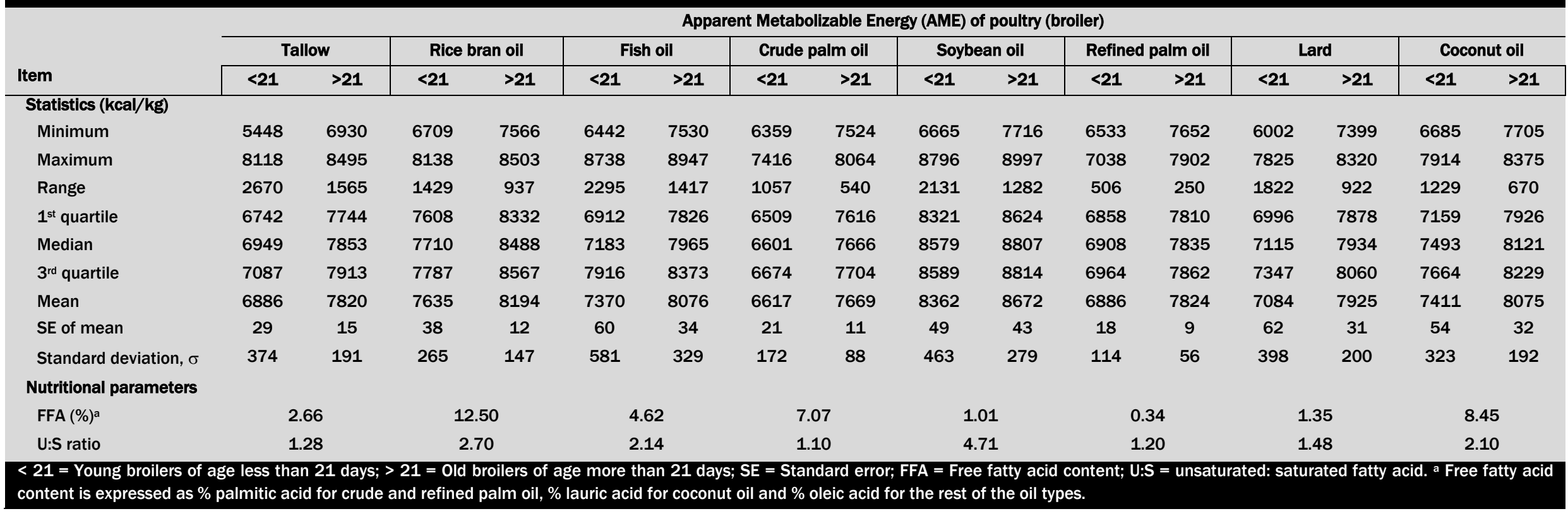

Table 4 - Details of samples collected from the different countries for the three major oil types (Tallow, rice bran oil and fish oil), with minimum, maximum, range and mean apparent metabolizable energy (AME) of young broilers (<21 days)

\begin{tabular}{|c|c|c|c|c|c|c|c|c|c|c|c|c|c|c|c|c|c|c|}
\hline \multirow{3}{*}{ Country } & \multicolumn{6}{|c|}{ Tallow } & \multicolumn{6}{|c|}{ Rice bran oil } & \multicolumn{6}{|c|}{ Fish oil } \\
\hline & \multicolumn{4}{|c|}{ AME (< 21 days) (kcal /kg) } & \multirow[b]{2}{*}{$\mathbf{n}$} & \multirow[b]{2}{*}{$\mathbf{n}_{\mathbf{s}}$} & \multicolumn{4}{|c|}{ AME (< 21 days) (kcal/kg) } & \multirow[b]{2}{*}{$\mathbf{n}$} & \multirow[b]{2}{*}{$\mathbf{n}_{\mathbf{s}}$} & \multicolumn{4}{|c|}{ AME (< 21 days) (kcal/kg) } & \multirow[b]{2}{*}{$\mathbf{n}$} & \multirow[b]{2}{*}{$\mathrm{n}_{\mathbf{s}}$} \\
\hline & Min & Max & $\mathbf{R}$ & Mean & & & Min & Max & $\mathbf{R}$ & Mean & & & Min & Max & $\mathbf{R}$ & Mean & & \\
\hline Thailand & - & - & - & - & 0 & - & 6709 & 8138 & 1429 & 7635 & 147 & 7 & 6442 & 8738 & 2295 & 7367 & 25 & 5 \\
\hline Indonesia & - & - & - & - & 0 & - & - & - & - & - & 0 & - & 6499 & 8425 & 1926 & 7416 & 34 & 4 \\
\hline Vietnam & 6299 & 6333 & 35 & 6316 & 2 & - & - & - & - & - & 0 & - & 6575 & 8321 & 1746 & 7103 & 24 & 9 \\
\hline Philippines & 5448 & 6561 & 1112 & 5989 & 6 & 1 & - & - & - & - & 0 & - & 7919 & 8233 & 313 & 8028 & 3 & 1 \\
\hline Singapore & 5826 & 6372 & 546 & 6138 & 3 & 1 & - & - & - & - & 0 & - & 7199 & 7199 & 0 & 7199 & 1 & 1 \\
\hline Taiwan & 6002 & 6640 & 638 & 6345 & 10 & 2 & - & - & - & - & 0 & - & 7440 & 7826 & 386 & 7633 & 2 & 1 \\
\hline South Korea & 6240 & 8118 & 1878 & 7003 & 138 & 5 & - & - & - & - & 0 & - & 7948 & 7948 & 0 & 7948 & 1 & 1 \\
\hline New Zealand & 6073 & 6520 & 448 & 6370 & 3 & 2 & - & - & - & - & 0 & - & 7861 & 8309 & 448 & 8031 & 3 & 1 \\
\hline India & 6503 & 6503 & 0 & 6503 & 1 & 1 & - & - & - & - & 0 & - & - & - & - & - & 0 & - \\
\hline Total & 5448 & 8118 & 2670 & 6886 & 163 & 12 & 6709 & 8138 & 1429 & 7635 & 147 & 7 & 6442 & 8738 & 2295 & 7370 & 93 & 23 \\
\hline
\end{tabular}

AME $(<21$ days $)=$ Apparent metabolizable energy for young broilers of age less than 21 days; Min = Minimum; Max = Maximum; $R=$ Range; $n=$ number of observations; $n s=$ number of suppliers. 
Table 5 - Details of tallow samples collected from South Korea, Supplier 1, with minimum, maximum, range calculated for apparent metabolizable energy (AME) of young broilers ( $<21$ days)

\begin{tabular}{lcccccc}
\hline Batch & AME (<21 days) (kcal/kg) & Count & Min & Max & R & $\begin{array}{c}\text { Percentage } \\
\text { variation (\%) }\end{array}$ \\
\hline Batch 1 & 26 & 6240 & 7303 & 1063 & 17 \\
Batch 2 & 7 & 6546 & 7124 & 578 & 9 \\
Batch 3 & 24 & 6612 & 7428 & 815 & 12 & 12 \\
Batch 4 & 22 & 6710 & 7488 & 778 & 783 & 12 \\
Batch 5 & 18 & 6630 & 7413 & 7258 & NA \\
Batch 6 & 1 & 7258 & 7258 & 0 & NA \\
Batch 7 & 1 & 7173 & 7173 & 0 & 3 \\
Batch 8 & 9 & 6908 & 7137 & 230 & 3
\end{tabular}

AME $(<21$ days $)=$ Apparent metabolizable energy for young broilers of age less than 21 days; Min = Minimum; Max = Maximum; $R=$ Range NA $=$ Not Applicable
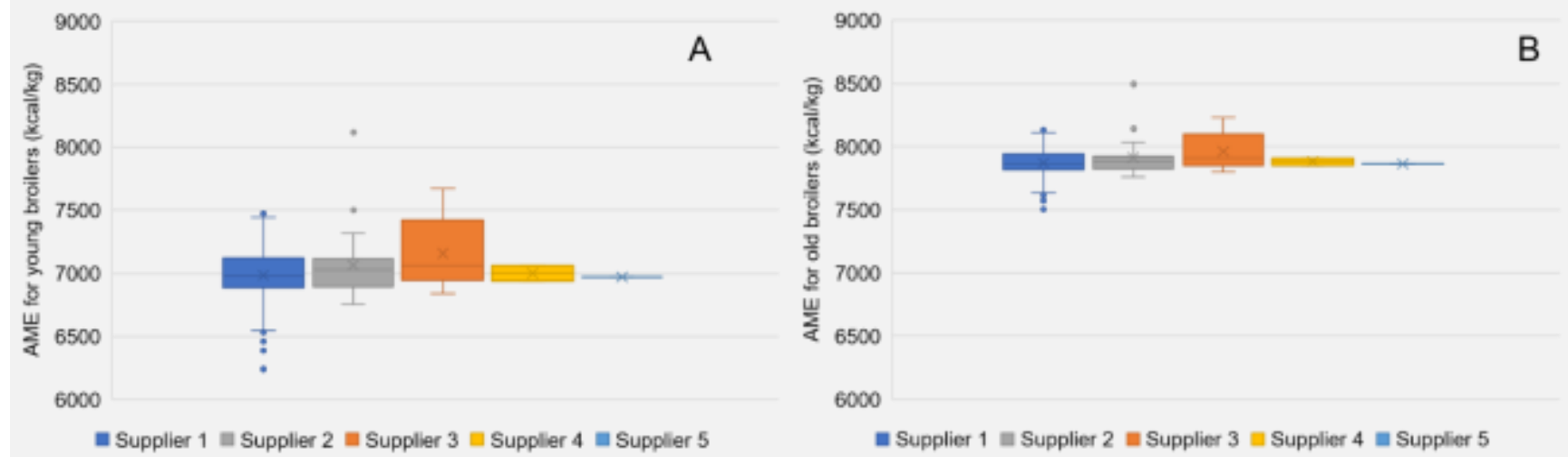

Figure 1 - Variations in minimum, first quartile, median, third quartile and maximum in predicted apparent metabolizable energy (AME) for both (A) young broilers (aged < 21 days) and (B) old broilers (aged $>21$ days) differentiated by the different tallow suppliers in South Korea.

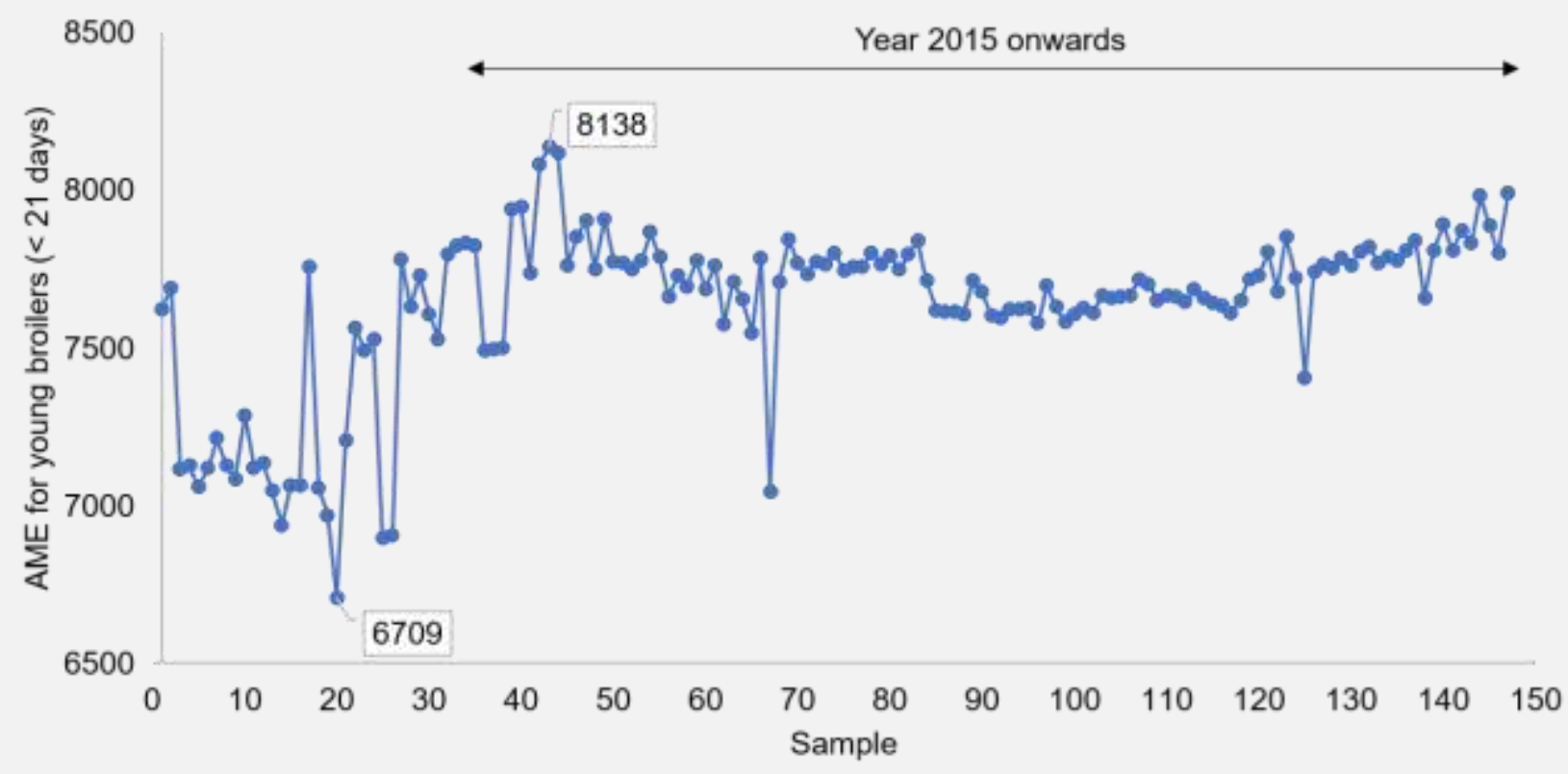

Figure 2 - Predicted apparent metabolizable energy (AME) trend graph for young broilers (aged < 21 days) with emphasis on year 2015 onwards, for rice bran oils. 


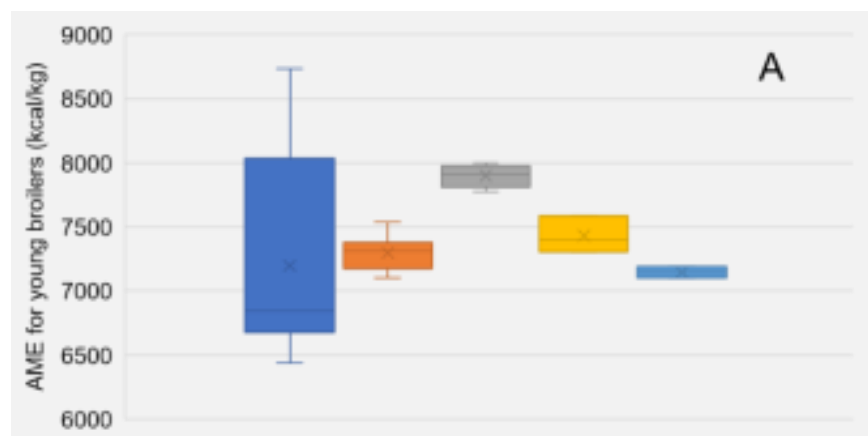

E Supplier A a Supplier B $=$ Supplier C e Supplier D $=$ Supplier E

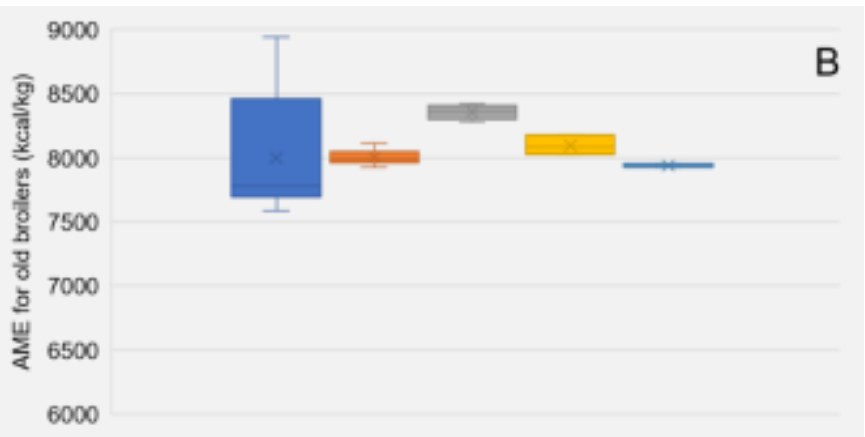

= Supplier A = Supplier B a Supplier C E Supplier D = Supplier E

Figure 3 - Variations in minimum, first quartile, median, third quartile and maximum in predicted apparent metabolizable energy (AME) for both (A) young broilers (aged $<21$ days) and (B) old broilers (aged $>21$ days) differentiated by the different fish oil suppliers in Thailand.

\section{CONCLUSION}

In conclusion, our data suggested that there is a considerable variation of the AME values in oils and fats. The AME variation that existed across oil samples from different regions and even within batches from similar suppliers may affect the feed formulation precision if the variation remains unaccounted for. Generic lipid energy values extracted from the traditional feed table were typically inaccurate as the animal species and age dependent metabolism were likely not considered in these tables. Furthermore, poor storage and processing conditions may deteriorate the oil quality as well. Inevitably, inconsistent AME values will not only contribute to huge economic losses but may also impact the animal performances adversely due to inaccurate feed formulations that fail to meet the caloric requirements of the animals. In view of these concerns, it is important to have a proper lipid evaluation tests in place for a more accurate lipid profile (e.g. AME value) estimation. Additionally, oil quality parameters such as peroxide and p-anisidine values should also be considered for oxidative stability evaluation as oil and fat quality may deteriorate over time. To improve oil and fat qualities, bio-emulsifiers and antioxidants can be used concurrently to improve oil and fat qualities in the context of oxidative stability and feed fat variability control.

\section{DECLARATIONS}

\section{Corresponding Authors}

Agnes Thng, e-mail: agnes.thng@kemin.com. Jun Xiang Ting, email: junxiang.ting@kemin.com. Hui Ru Tay, email: huiru.tay@kemin.com. Chin Yi Soh, email: chinyi.soh@kemin.com. Hwee Ching Ong, email: hweeching.ong@kemin.com. David Tey, email: david.tey@kemin.com.

\section{Authors' Contribution}

A. Thng proposed the design of study, prepared the manuscript and performed the laboratory analysis. J.X. Ting, H.R. Tay, C.Y. Soh and H.C. Ong assisted with the laboratory analyses. D. Tey reviewed and edited the manuscript.

\section{Conflict of interests}

The authors declared that there is no conflict in this study.

\section{Acknowledgements}

The authors thank the suppliers from the Asia Pacific region for the collection of oil and fat samples. We also thank Dr C. Sugumar for his scientific contributions in this study, and Ms R.Lye, Drs J. Tan, K.P. Chan and H. Chirakkal for their constructive feedbacks on the manuscript draft. This study was supported by Kemin Industries (Asia) Pte Limited, Animal Health and Nutrition.

\section{REFERENCES}

Ahiwe E, Omede AA, Abdallh MEB and lji PA (2018). Managing dietary energy intake by broiler chickens to reduce production costs and improve product quality. IntechOpen, London, UK, pp 115 - 145. Google Books I ResearchGate

AOAC (2012). Association of Official Analytical Chemists. Official method of analysis, $19^{\text {th }}$ Edition. Washington D.C. pp. 12. http://www.aoacofficialmethod.org/index.php?main_page=product_info\&cPath=1\&products_id=2902

AOAC (2012). Association of Official Analytical Chemists. Official method of analysis, 19th Edition. Washington D.C. pp. 19-20. http://www.aoacofficialmethod.org/index.php?main_page=product_info\&cPath=1\&products_id=1733

Baião NC and Lara LJC (2005). Oil and fat in broiler nutrition. Brazilian Journal of Poultry Science 7(3): 129-141. Dol: https://doi.org/10.1590/S1516-635X2005000300001 
Blair R (2018). Nutrition and feeding of organic poultry, 2nd Edition. Centre for Agriculture and Bioscience International (CABI), England, UK, pp 94-95. Google Books

Codony R, Guardiola F, Tres A and Barroeta AC (2017). Quality control and nutritional value of fats. In: M. Francesch et al. (Editors), Proceedings of the 21st European Symposium on Poultry Nutrition: Plenary session 06. Hot Topics: sustainability on poultry feeding, Salou/Vila-seca, Spain, pp. 118-123. Google Books

Dominguez R, Pateiro M, Gagaoua M, Barba FJ, Zhang W and Lorenzo JM (2019). A comprehensive review on lipid oxidation in meat and meat products. Antioxidants 8(10): 429. DOI: $10.3390 /$ antiox8100429

European Food Safety Authority (EFSA) Panel on Biological Hazards (BIOHAZ) (2010). Scientific opinion on fish oil for human consumption. Food hygiene, including rancidity. EFSA Journal 8(10): 1874. https://efsa.onlinelibrary.wiley.com/doi/pdf/10.2903/i.efsa.2010.1874

Food and Agricultural Organization of the United Nations World Health Organization (FAO/WHO) (2001). Codex Alimentarius: Fats, oils and related products, volume 8. Joint FAO/WHO, Rome, Italy. http://www.fao.org/3/y27744e/y2774e00.htm\#Contents

Food and Agricultural Organization of the United Nations World Health Organization (FAO/WHO) (2017). Codex Alimentarius Commission. Standard for fish oils codex stan 329. Joint FAO/WHO, Rome, Italy. https://www.iffo.net/system/files/Codex\%20Standard\%20for\%20Fish\%200ils\%20CXS 329e Nov\%202017.pdf

Gibson M and Newsham P (2018). Lipids, oils, fats, and extracts. In: Gibson M and Newsham P (Editors), Food science and the culinary arts, chapter 16, pp. 323-340. Academic Press, Cambridge, US. https://doi.org/10.1016/B978-0-12-811816-0.00016-6

Goffman FD and Bergman C (2003). Relationship between hydrolytic rancidity, oil concentration and esterase activity in rice bran. Cereal Chemistry 80(6): 689-692. https://doi.org/10.1094/CCHEM.2003.80.6.689

Hofmann AF and Borgstrom B (1962). Physico-chemical state of lipids in intestinal content during their digestion and absorption. Federal Proceedings 21: 43-50. https://pubmed.ncbi.nlm.nih.gov/13908158/

Lall SP and Dumas A (2005). Nutritional requirements of cultured fish: Formulating nutritionally adequate feeds. In: D. Allen Davis (Editor), Food Science, Technology and Nutrition. Feed and Feeding Practices in Aquaculture. Sawton, Cambridge, UK, pp 53-109. https://doi.org/10.1016/B978-0-08-100506-4.00003-9

Niu Z, Shi J, Liu F, Wang X, Gao C and Yao L (2009). Effects of dietary energy and protein on growth performance and carcass quality of broilers during starter phase. International Journal of Poultry Science 8(5): 508-511. DOI: 10.3923/ijps.2009.508.511

Pond WG, Church DB, Pond KR, Schoknecht PA (2004). Basic animal nutrition and feeding, $5^{\text {th }}$ Edition. John Wiley \& Sons, Inc., New Jersey, USA, pp. 40-41. Google Books

Rajan RGR and Krishna AGG (2009). Refining of high free fatty acid rice bran oil and its quality characteristics. Journal of Food Lipids 16(4): 589 - 604. https://doi.org/10.1111/j.1745-4522.2009.01168.x

Ravindran V, Tancharoenrat P, Zaefarian F and Ravindran G (2016). Fats in poultry nutrition: Digestive physiology and factors influencing their utilisation. Animal Feed Science and Technology 213: 1-21. https://doi.org/10.1016/j.anifeedsci.2016.01.012

Rodriguez-Sanchez R, Tres A, Sala R, Guardiola F and Barroeta AC (2019). Evolution of lipid classes and fatty acid digestibility along the gastrointestinal tract of broiler chickens fed different fat sources at different ages. Poultry Science 98(3): 1341-1353. http://dx.doi.org/10.3382/ps/pey458

Rodriguez-Sanchez R, Tres A, Sala R, Garcés-Narro C, Guardiola F, Gasa J and Barroeta AC (2019). Effects of dietary free fatty-acid content and saturation degree on lipid-class composition and fatty-acid digestibility along the gastrointestinal tract in broiler starter chickens. Poultry Science 98(10): 4929-4941. https://doi.org/10.3382/ps/pez253

Scanes CG and Christensen KD (2019). Poultry Science, $5^{\text {th }}$ Edition. Waveland Press, Inc., Illinois, USA, pp. 65. Google Books

Sklan D (1979). Digestion and absorption of lipids in chicks fed triglycerides or free fatty acids: synthesis of monoglycerides in the intestine. Poultry Science 58(4): 885-889. DOI: 10.3382/ps.0580885

Tancharoenrat P, Ravindran V, Zaefarian F and Ravindran G (2014). Digestion of fat and fatty acids along the gastrointestinal tract of broiler chickens. Poultry Science 93(2): 371 - 379. https://doi.org/10.3382/ps.2013-03344

Vallabha VS, Indira TN, Lakshmi AJ, Radha C and Tiku PK (2015). Enzymatic process of rice bran: a stabilized functional food with nutraceuticals and nutrients. Journal of Food Science and Technology 52(12): 8252-8259. DOI: 10.1007/s13197-015-1926-9

Wiseman J and Blanch A (1994). The effect of free fatty acid content on the apparent metabolizable energy of coconut/palm kernel oil for broiler chickens aged 12 and 52 days. Animal Feed Science and Technology 47(3-4): 225-236. https://doi.org/10.1016/0377-8401(94)90126-0

Wiseman J, Powles J and Salvador F (1998). Comparison between pigs and poultry in the prediction of the dietary energy value of fats. Animal Feed Science and Technology 71(1-2): 1-9. https://doi.org/10.1016/S0377-8401(97)00142-9

Wiseman J and Salvador $F$ (1991). The influence of free fatty acid content and degree of saturation on the apparent metabolizable energy value of fats fed to broilers. Poultry Science, 70(3): 573-582. DOI: 10.3382/ps.0700573 